\title{
Is Social Media Changing the Awareness of Individuals?
}

\author{
Tom Sander ${ }^{1}$ and Phoey Lee Teh ${ }^{2}$ \\ ${ }^{I}$ Communication and Public Understanding of Economics, New College of the Humanities, UK. \\ ${ }^{2}$ Department of Computing and Information System, School of Science and Technology, Sunway University, \\ Malaysia.
}

\begin{abstract}
.
Social media has provided a platform for fake news, which most individuals distribute without realizing that it is fake news. Fake news distribution hinges on individuals' awareness of information. The current study aimed to examine information awareness and assimilation among users of social media. Based on the collective action theory, the study conducted an online survey comprising Facebook and Instagram users and analysed 143 datasets. The results implied that social media is responsible for influencing the awareness of individuals, which in turn allows for fake news to be easily distributed.
\end{abstract}

Keywords: Social media, Fake news, Information awareness, Collective Action Theory

\section{INTRODUCTION}

The growing influence of social and digital media has changed the way we communicate. Social media platforms, such as Facebook, have dramatically changed how information is disseminated (Allcott \& Gentzkow, 2017). Information is relayed among social media users so quickly that often no filtering or fact-checking on the information is done, which can be harmful and damaging (Teh, Huah, \& Si, 2014). Misleading information could disrupt societal interactions and damage individual lives (Torres \& Gerhart, 2018). As such, there is a need to investigate how behaviour and decision-making are influenced by social media (Simeone \& Russo, 2017).

Many individuals use social media platforms to share or distribute "news" or knowledge to their social circles or other social media users (Ragunathan et al., 2015). These platforms are usually online social networking sites such as Facebook and Instagram (Mcfarland \& Ployhart, 2015; Sander, Sloka \& Puke, 2017) Information relayed on social media has an influence over the behaviour of individuals resulting in social media being used for various purposes-product marketing, political campaigning, information circulation, etc. For instance, companies that wish to market new products could advertise on social media by generating many likes and comments on their online posts to attract customers (Khoo, Teh, \& Ooi, 2017). Existing or prospective customers would then "follow" the companies" aggregated news for more information about them or their products (Parganas, Anagnostopoulos, \& Chadwick, 2017).

Unfortunately, social media platforms also provide an avenue for fake news to be disseminated. Fake news are usually distorted pieces of news or untruthful accounts of a particular event, which could be created unintentionally or on purpose with people augmenting the information (e.g., omit or add information, make up stories, present information in the wrong context, etc.) when sharing it with others. Research has found fake 
news to influence society and have an impact on the economic or political decisions of readers (Bakir \& McStay, 2017; Ross \& Rivers, 2018). Social media platforms have hence become a leading media tool with heavy influence on the beliefs of individuals.

With today's artificial intelligence and algorithms, social media platforms are able to perform filter bubbles where information presented to an individual is tailored according to the individual's interests. For example, individuals that post political views on social media will eventually only be shown information relevant to their posts, which would influence or reinforce their own opinion or political direction. Most individuals are also not used to seeking alternative sources of information (Geschke, Lorenz, \& Holtz, 2019) and as such, live in a media bubble. Hence, there is a lack of awareness in spotting and distinguishing fake news from real ones.

This lack of awareness is made more salient when the same news is presented to the individual numerous times via different media channels. Known as "echo chamber", such a situation would increase the likelihood of individuals believing the fake news to be real (Vergeer, 2014). This happens mainly on social media due to the filter bubble action of the website's algorithm. Many individuals might believe a particular news to be true without analysing it critically and such "bias perception" would prompt the individuals to search for similar information to strengthen their beliefs. These individuals would then only believe in information that support their own views (Torres \& Gerhart, 2018). Thus, the dissemination of fake news on social media increases.

According to collective action theory, piggybacking refers to free riding on and taking advantage of the efforts of certain groups on social media. Individuals are motivated to create groups and social movements on social media to influence society in disseminating the information that these individuals wish to convey (Priante \& Need, 2018) It is highly likely that most individuals would be influenced by the information they receive but not critically analyse it, which therein lies the danger of fakes news on social media.

The current study examined information awareness and assimilation among users of social media. Data was collected from an online questionnaire and analysed using various statistical methods, t-test and correlation. The study assumed that social media influence the information awareness of individuals, making it harder for individuals to differentiate fake news from real ones. Unaware that they have assimilated fake news, these individuals would then unintentionally circulate the fake news on social media which would reach out to more individuals.

\section{COLLECTIVE ACTION THEORY AND INFORMATION AWARENESS}

The collective action theory describes how an unorganised mass of individuals with individual choices and interests have the power to change or influence economic, political, or technological developments (Priante \& Need, 2018). According to the theory, rules and identity are important elements that create the collective behaviour of this unorganised mass. When individuals in the mass have a shared objective, norms, structures, and boundaries surrounding it are formed. Thus, individuals begin to identify with the mass and are considered "in-group", while those outside of the mass are considered "out-group" (Dai \& Walther, 2018). The in-group shows solidarity and supports one another to achieve an 
objective, and its opposition against the out-group strengthens the mass and pushes it to organise social movements.

Social movements are typically and deliberately constructed with shared objectives, rules, and identity. Typical social movements are collective protests, such as against a government decision or on an environmental issue. The members of such social movements are usually from different social groups, parties, etc., but they share a collective interest to change something and hence, align themselves with the movement or group behind the movement (Juris, 2004). Individuals are motivated to take part in collective action with the belief that it would be easier to achieve a desirable result if they work together as a group than on their own. As a group, there is a unified sense of identity and higher likelihood to achieve the collective objective (Koppenjan \& Groenewegen, 2005). However, many individuals may participate in a movement but not necessarily have a full understanding of it.

Social media provides a platform for collective action and social movement. For example, numerous news on environmental issues and crises increase the awareness of individuals with regards to information related to the environment. This increased awareness might motivate like-minded individuals to band together to take action. Social media supports swift collective actions to be taken, such as the push for the adoption of metal straws for cleaner oceans (i.e., reduced plastic usage).

Social media also provides an opportunity for social control where wrong behaviour can be penalised or sanctioned by users (Sander, Teh, \& Sloka, 2017). This could occur through emobilisation, e-movement, and e-tactics. E-mobilisation refers to social media being used to organise and coordinate protests, demonstrations, or boycotts offline (i.e., on the streets in the real world). On the other hand, e-movement refers to social media being used to hold protests, demonstrations, or boycotts online. For example, distributed denial-of-service attacks on computer systems. The combination of both e-mobilisation and e-movement is known as etactics (Kende, Zomeren, Adrienn, \& Lantos, 2016). Groups or social movements on social media are effective as they can be coordinated at minimal cost (Dolata \& Schrape, 2015).

Collective action is also more effective when the involved individuals' emotions are heightened. How one feels about a particular collective action could influence one's behaviour and provide a reason to follow the particular group or social movement. This is particularly so when the emotions are compounded with a sense of injustice that the individuals experience. For example, environmentalists who learn of an oil company carrying out harmful practices that affect the environment would react by boycotting it (Kende et al., 2016). They would also try to persuade others to join them in their boycott.

On social media, emotions are expressed in a variety of formats through written comments. For instance, capital letters, repeated vowels, and exclamation marks that are fine-grained in computer-mediated communications (CMC) have the ability to influence or augment an individual's perception (Teh et al., 2015). The use of emoticons in messages also has the potential to change an individual's opinion (Teh et al., 2016). The type of consumption emotion that users experience on the various social media platforms is an important factor to consider in online communication (Jin et al., 2017). Apart from that, the behaviour of individuals is also influenced by cultural factors (O'Leary, 2010). 


\section{METHOD}

Data was collected from April 2018 to June 2018 via an online survey that was distributed through social networking sites. Online surveys are effective and suitable for internet research (Wright, 2006). The online survey used in the current study comprised several questions pertaining to participants' opinions on social media, which were scored on a scale ranging from 1 (full agreement) to 6 (full disagreement). The current study only used 144 records from the data.

The participants were German speakers, of which $63.64 \%$ were female and $36.36 \%$ were male. The median age of the participants was 22 years and the mode age was 19 years $(\mathrm{n}=$ 144), implying that the participants were young individuals familiar with today's technologies. In terms of education level, majority of the participants have a high school standard $(43.75 \%)$ and were university students $(51.39 \%)$. Table 1 presents the total participants' employment status and education level, both in Instagram and Facebook

The online survey also comprised open-ended questions pertaining to participants' usage pattern of Facebook and Instagram (Table 1). The usage pattern was measured based on the number of friends/followers the participants have on the platform, how much time they spend on the platform per day, and how often they post or like a post per week on the platform. These questions with regards to the participants' usage pattern on Facebook and Instagram were similar to the ones used in past studies (Sander \& Teh, 2014; Wilson, Gosling, \& Graham, 2012).

Table 1 The usage pattern of participants on Facebook and the usage pattern of participants on Instagram.

\begin{tabular}{|l|l|l|l|l|l|l|}
\hline Usage Patterns (Facebook) & $\mathrm{n}$ & Mean & Median & Std. Deviation & Min & Max \\
\hline Number of friends & 116 & 431.72 & 357 & 428.07 & 0 & 3000 \\
\hline Time spent per day (in minutes) & 119 & 30.94 & 20 & 40.88 & 0 & 280 \\
\hline Number of posts/likes per week & 111 & 6.92 & 1 & 14.42 & 0 & 100 \\
\hline Usage Patterns (Instagram) & $\mathrm{n}$ & Mean & Median & Std. Deviation & Min & Max \\
\hline Number of followers & 108 & 240.79 & 200 & 266.43 & 0 & 1800 \\
\hline Time spent per day (in minutes) & 104 & 58.38 & 40 & 62.06 & 0 & 280 \\
\hline Number of posts/likes per week & 96 & 26.21 & 3 & 52.09 & 0 & 300 \\
\hline
\end{tabular}

\section{RESULTS}

The purpose of the study was to examine if social media is capable of influencing the information awareness of individuals. Table 2 presents the results of the online survey, which comprised questions pertaining to the participants' opinions on social media. Figure 1 presents the participants' score distribution of the online survey.

From the results, it can be observed that $54.2 \%$ of participants fully agreed that social media can indeed influence the awareness of individuals (mean $=1.65$, median $=1$ ). Besides that, $57.6 \%$ of participants also fully agreed that individuals tend to present themselves more positively on social media than in reality $($ mean $=1.72$, median $=1)$. These results imply that participants believed that individuals are aware of social media having an influence on feelings of justification. 
International Conference on NEW TRENDS IN SOCIAL SCIENCES

5-7 September, 2019

BARCELONA, SPAIN

Table 2. Results of the online survey $(n=142-144)$

\begin{tabular}{|l|l|l|}
\hline Opinions & $\mathrm{n}$ & $\mathrm{Mean}$ \\
\hline Individuals present themselves more positively on social media than in reality & 144 & 1.72 \\
\hline Social media can influence the awareness of individuals & 144 & 1.65 \\
\hline Information about disasters are exaggerated on social media & 144 & 2.15 \\
\hline $\begin{array}{l}\text { The amount of information on social media makes it difficult for individuals to evaluate } \\
\text { information correctly }\end{array}$ & 144 & 2.16 \\
\hline Social media supports fake news propagation & 143 & 2.31 \\
\hline I receive more recognition on social media for my activities/posts (success) than in reality & 142 & 4.2 \\
\hline
\end{tabular}

Feelings of justification come about when individuals experience an emotion towards an action that they think is fair or unfair, right or wrong. If an action is fair or right, they experience a sense of justice whereas if an action is unfair or wrong, there is a sense of injustice and an attempt to correct the correct. However, there are also individuals who attempt to justify their actions despite being aware that what they are doing is unfair or wrong. This is known as self-serving justification. In terms of information presentation on social media, it can be implied that individuals are aware that what they see online could be positively presented in their favour and hence, not always necessarily accurate. However, despite knowing this, most individuals still trust and accept information online without analysing it critically.

Figure 1. Score distribution of online survey

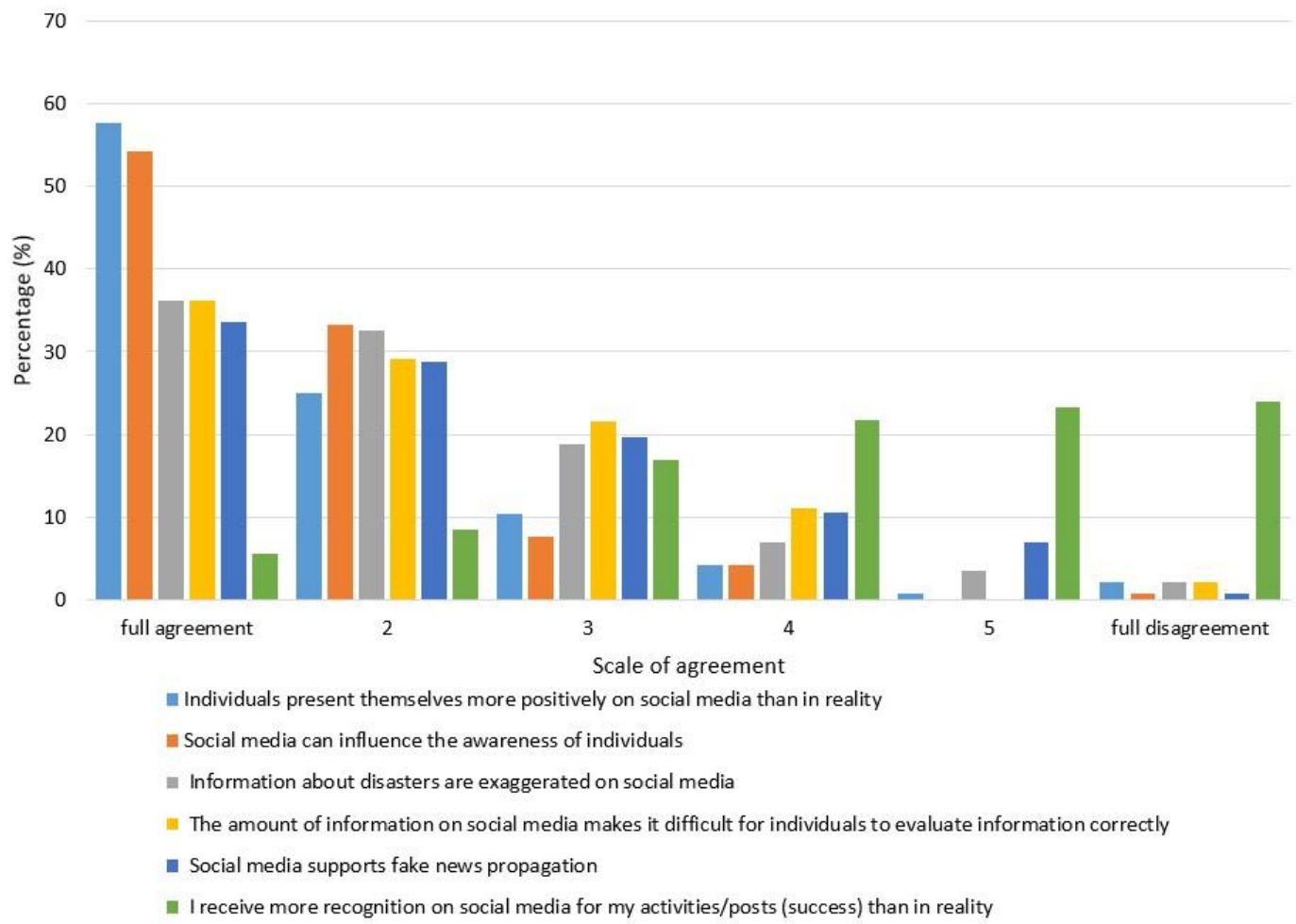

Besides that, a total of $68.7 \%$ of participants agreed (those that scored 1 or 2 in the survey) that information about disasters on social media are exaggerated. Participants also agreed that it is hard to determine the genuineness of information due to the amount of information available on social media $(65.3 \%)$, and that social media supports fake news propagation 
$(62.3 \%)$. These results imply that social media is believed to serve as a platform for fake news or exaggerated news, and that the overload of information online that individuals encounter makes it easier for such news to be passed on as real news. In addition, only $14.1 \%$ of participants agreed that they receive more recognition and success online than in the real world.

Gender differences were only apparent for the statement on "individuals present themselves more positively on social media than in reality". The results of the t-test analysis (Table 3) was supported by the results from the Pearson's chi-squared ( $\mathrm{p}=0.019$, likelihood quotient $=0.012$ ).

Table 3 The results of the $t$-test in measuring for gender differences $(n=143)$

\begin{tabular}{|c|c|c|c|c|c|c|c|c|}
\hline & \multicolumn{2}{|c|}{$\begin{array}{l}\text { Levene's Test fo } \\
\text { Equality } \\
\text { Variances }\end{array}$} & \multicolumn{5}{|c|}{ T-test for Equality of Means } \\
\hline & & $\mathrm{F}$ & Sig. & $\mathrm{t}$ & df & $\begin{array}{l}\text { Sig. (2- } \\
\text { tailed) }\end{array}$ & $\begin{array}{l}\text { Mean } \\
\text { Difference }\end{array}$ & $\begin{array}{l}\text { Std. Error } \\
\text { Difference }\end{array}$ \\
\hline \multirow{2}{*}{$\begin{array}{l}\text { Individuals } \\
\text { present } \\
\text { themselves } \\
\text { more positively } \\
\text { on social media } \\
\text { than in reality }\end{array}$} & $\begin{array}{l}\text { Equal } \\
\text { variances } \\
\text { assumed }\end{array}$ & 6.084 & 0.015 & 2.712 & 141 & 0.008 & 0.500 & 0.184 \\
\hline & $\begin{array}{l}\text { Equal } \\
\text { variances not } \\
\text { assumed }\end{array}$ & & & 2.403 & 74.168 & 0.019 & 0.500 & 0.208 \\
\hline
\end{tabular}

The largest score difference between male and female participants was for the "1 (full agreement)" rating (18\%; Figure 2). A total of $95 \%$ of female participants selected the ratings of 1,2 , or 3 , but none selected the ratings of 5 or 6 . Overall, the majority of both male and female participants selected the " 1 (full agreement)" rating.

Figure 2. Individual present themselves more positively on social media than in reality (between Female and Male)

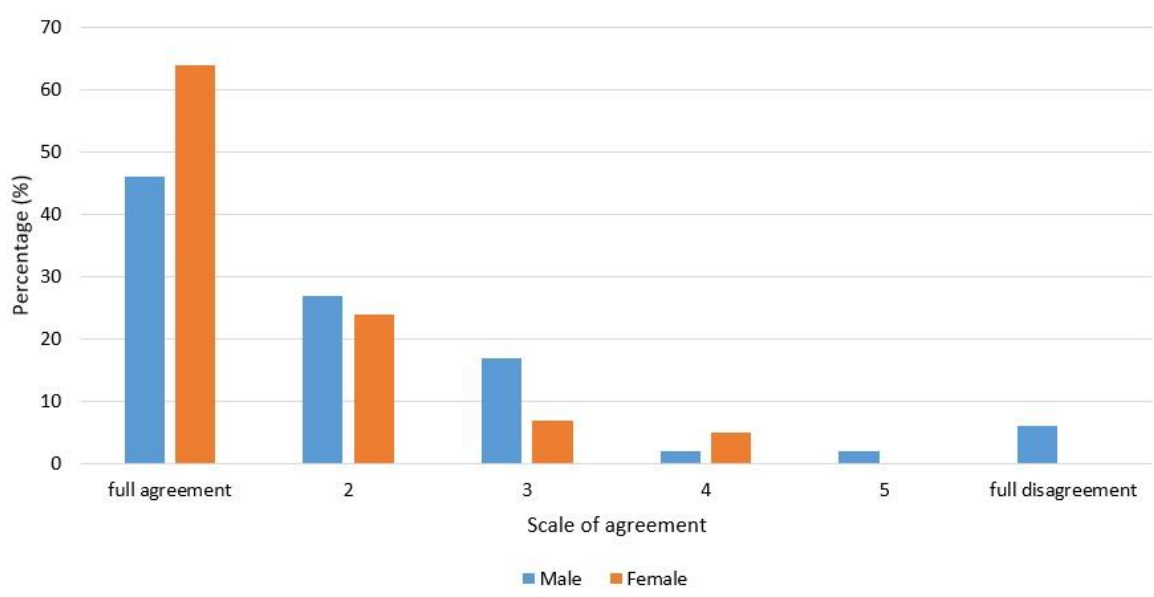

However, both correlations were found to be weak and negative. The negative correlations indicate that Facebook users with a higher number of friends on the platform tend to be less agreeable to the two statements. Hence, despite the small effect size, the results imply that a user's number of friends on Facebook should be taken into account when researching on social media user behaviour. 
International Conference on NEW TRENDS IN SOCIAL SCIENCES

5-7 September, 2019

BARCELONA, SPAIN

Table 4 The statistically significant results of the Spearman's correlation analysis for Facebook

\begin{tabular}{|c|c|c|}
\hline & & Number of friends \\
\hline \multirow[t]{2}{*}{ Information about disasters are exaggerated on social media } & Spearman's coefficient & -0.191 \\
\hline & Sig. (2-tailed) & 0.040 \\
\hline \multirow{2}{*}{$\begin{array}{l}\text { I receive more recognition on social media for my } \\
\text { activities/posts (success) than in reality }\end{array}$} & Spearman's coefficient & -0.264 \\
\hline & Sig. (2-tailed) & 0.004 \\
\hline
\end{tabular}

Table 5 presents only the statistically significant results of the Spearman's correlation analysis for Instagram. The statements "individuals present themselves more positively on social media than in reality" and "I receive more recognition on social media for my activities/posts (success) than in reality" were the only ones that have statistically significant correlations with "number of followers" for Instagram users. Similar to the results found for Facebook, these correlations were weak and negative. However, the number of followers on Instagram showed no statistically significant correlation with the statement "information about disasters are exaggerated on social media" unlike the results for Facebook.

Table 5 The statistically significant results of the Spearman's correlation analysis for Instagram

\begin{tabular}{|c|c|c|}
\hline & & Number of followers \\
\hline \multirow{2}{*}{$\begin{array}{l}\text { Individuals present themselves more positively on social } \\
\text { media than in reality }\end{array}$} & Spearman's coefficient & -0.227 \\
\hline & Sig. (2-tailed) & 0.018 \\
\hline \multirow{2}{*}{$\begin{array}{l}\text { I receive more recognition on social media for my } \\
\text { activities/posts (success) than in reality }\end{array}$} & Spearman's coefficient & -0.297 \\
\hline & Sig. (2-tailed) & 0.002 \\
\hline
\end{tabular}

From the results, it can be observed that the statement "I receive more recognition on social media for my activities/posts (success) than in reality" have negative correlations with both Facebook and Instagram. This could imply that social media users with higher numbers of friends/followers on either platform tend to be less agreeable with that statement. The reason to disagree with the statement is the increased knowledge and experience about social network sites. User of social network sites change their behaviour and the use of social media tools. The heavy user of social network sites perception regarding media and content is changing compared with normal user. This can lead to the result and is a potential explanation.

Interesting is that both correlations for Facebook and Instagram contacts with the items are negative. That means the higher the number of contacts the lower is the agreement regarding the awareness. The experience is influencing the result in an unexpected way and contrary to the general descriptive results. That means the subgroup of heavy user behave differently compared with the other user of social network sites and describes the influence of use on the perception of content and activities on Facebook and Instagram.

Table 6 presents only the statistically significant results of the Spearman's correlation analysis between participants' survey answers and participants' usage pattern regarding storing payment details online. The statements "individuals present themselves more positively on social media than in reality", "social media can influence the awareness of individuals", and "information about disasters are exaggerated on social media" were found to have weak but positive correlations with "frequency of payment details being stored online". These results indicate that social media users who trust social media enough with their payment details tend to agree with those three statements.

Table 6 The statistically significant results of the Spearman's correlation analysis for "frequency of payment details being stored online"

\begin{tabular}{|l|l|}
\hline & Frequency of payment details being \\
\hline
\end{tabular}
stored online 


\begin{tabular}{|l|l|l|}
\hline Individuals present themselves more & Spearman's coefficient & 0.200 \\
\cline { 2 - 3 } positively on social media than in reality & Sig. (2-tailed) & 0.027 \\
\hline $\begin{array}{l}\text { Social media can influence the awareness of } \\
\text { individuals }\end{array}$ & Spearman's coefficient & 0.256 \\
\cline { 2 - 3 } & Sig. (2-tailed) & 0.004 \\
\hline Information about disasters are exaggerated & Spearman's coefficient & 0.233 \\
\cline { 2 - 3 } on social media & Sig. (2-tailed) & 0.009 \\
\hline
\end{tabular}

Overall, the results indicate that only the number of friends/followers on a social networking platform and the level of trust individuals have in storing their payment details online were found to be correlated with a few of the survey's statements as shown in Tables 4, 5 , and 6. The statement "social media can influence the awareness of individuals" only has a positive correlation with "frequency of payment details being stored online".

\section{CONCLUSION}

The current study aimed to examine information awareness and assimilation among users of social media. The results indicated that majority of social media users are aware of how social media can influence information awareness and assimilation, such as allowing for fake news propagation and the exaggeration of information about disasters. The results also indicated that the individuals' number of friends/followers on social networking platforms have a negative influence on the individuals' beliefs.

No differences were found in the individuals' awareness level with regards to employment status or educational level. This could mean that regardless of level of employment or education, social media (i.e., number of friends/followers) is responsible for changing the awareness of individuals. In other words, social media is responsible for distributing fake news and influencing individual beliefs. Individuals' perception of anger and feelings of justification can lead to social movements and collective actions. Social media provides an easy, quick, and low-cost platform for such behaviour. Further research should take into consideration the influence of fake news and change in awareness in different countries.

\section{REFERENCES}

[1] Allcott, H., \& Gentzkow, M. (2017). Social Media and Fake News in the 2016 Election, Journal of Economic Perspectives, 31(2), 211-236.

[2] Bakir, V., \& McStay, A. (2017). Fake News and The Economy of Emotions: Problems, causes, solutions. Digital Journalism, 0811, 1-22.

[3] Dai, Y., \& Walther, J. B. (2018). Vicariously Experiencing Parasocial Intimacy with Public Figures Through Observations of Interactions on Social Media. Human Communication Research, 44(3), 322-342.

[4] Dolata, U., \& Schrape, J. (2015). Masses , Crowds , Communities , Movements : Collective Action in the Internet Age. Social Movement Study. 15(1),1-18.

[5] Geschke, D., Lorenz, J., \& Holtz, P. (2019). The triple-filter bubble: Using agent-based modelling to test a meta-theoretical framework for the emergence of filter bubbles and echo chambers. British Journal of Social Psychology, 58(1), 129-149.

[6] Jin, Y., Lin, J. E., Gilbreath, B., \& Lee, Y. (2017). Motivations , Consumption Emotions , and Temporal Orientations in Social Media Use: A Strategic Approach to Engaging 
Stakeholders Across Platforms. International Journal of Strategic Communication, 11(2), 115-132.

[7] Juris, J. S. (2004). Networked social movements: global movements for global justice. In E. Elgar (Ed.), Network society, a cross cultural perspective (pp. 341-362). Cheltenham: Castells, Manuel.

[8] Kende, A., Zomeren, M. Van, Adrienn, U., \& Lantos, N. A. (2016). The social affirmation use of social media as a motivator of collective action, Journal of Applied Social Psychology. 46 (8), 453-469.

[9] Khoo, F. S., Teh, P. L., \& Ooi, P. B. (2017). Consistency of Online Consumer's Perceptions of Posted Comments: An Analysis of TripAdvisor Reviews. Journal of Information and Communication Technology, 2(2), 374-393.

[10] Koppenjan, J., \& Groenewegen, J. (2005). Institutional design for complex technological systems. Int. J. Technology, Policy and Management, 5(3), 240-257.

[11] Mcfarland, L. A., \& Ployhart, R. E. (2015). Social Media : A Contextual Framework to Guide Research and Practice. Journal of Applied Psychology, 100(6), 1653-1677.

[12] Parganas, P., Anagnostopoulos, C., \& Chadwick, S. (2017). Effects of social media interactions on brand associations: A comparative study of soccer fan clubs. International Journal of Sports Marketing and Sponsorship, 18(2), 149-165.

[13] Priante, A., \& Need, A. (2018). Identity and collective action communication: A review and agenda for future research. New media \& society, Vol. 20(7) 2647-2669.

[14] Ragunathan, T., Battula, S. K., Jorika, V., Mounika, C., Sruthi, A. U., \& Vani, M. D. (2015). Advertisement posting based on consumer behavior. Procedia Computer Science, 50, 329-334.

[15] Ross, A. S., \& Rivers, D. J. (2018). Discursive Deflection: Accusation of “ Fake News " and the Spread of Mis- and Disinformation in the Tweets of President Trump. Social Media + Society.

[16] Sander, T. and Teh, P. (2014) Determining the indicators of social capital theory to social network sites, 2014 3rd International Conference on User Science and Engineering (i-USEr), Shah Alam, 2014, pp. 264-268.

[17] Sander, T., Sloka, B., \& Puke, I. (2017). Differences in the exchange of contents of different countries in social network sites. International Journal of E-Collaboration, 13(2). 64-80.

[18] Sander, T., Teh, P. L., \& Sloka, B. (2017). Your Social Network Profile Reveals You. International Journal of Web Information Systems, 13(1), 14-24.

[19] Shalvi, S., Gino, F., Barkan, R., \& Ayal, S. (2015). Self-Serving Justifications: Doing Wrong and Feeling Moral. Current Directions in Psychological Science, 24(2), 125-130.

[20] Simeone, M., \& Russo, C. (2017). The growing influence of social and digital media. British Food Journal, 119(8), 1766-1780.

[21] Teh, P., Huah, L. P., \& Si, Y. (2014). The Intention to Share and Re-Shared among the Young Adults towards a Posting at Social Networking Sites. New Perspectives in Information Systems and Technologies, 1, 13-21. 
[22] Teh, P. L., Pak, I. Rayson, P. and Piao, S. (2015). Exploring fine-grained sentiment values in online product reviews, 2015 IEEE Conference on Open Systems (ICOS), Bandar Melaka, 2015, pp. 114-118.

[23] Teh, P. L., Rayson, P., Pak, I., Piao, S., \& Yeng, S. M. (2016). Reversing the Polarity with Emoticons. In E. Métais, F. Meziane, M. Saraee, V. Sugumaran, \& S. Vadera (Eds.), Natural Language Processing and Information Systems: 21st International Conference on Applications of Natural Language to Information Systems, NLDB 2016, Salford, UK, June 22-24, 2016, Proceedings (pp. 453-458). Cham: Springer International Publishing.

[24] Torres, R. R., \& Gerhart, N. (2018). Epistemology in the Era of Fake News : An Exploration of Information Verification Behaviors among Social Networking Site Users, ACM SIGMIS Database: the DATABASE for Advances in Information Systems. 49(3), 78-97.

[25] Vergeer, M. (2014). Peers and sources as social capital in the production of news: Online social networks as communities of journalists. Social Science Computer Review, 33(3), 277-297.

[26] Wilson, R. E., Gosling, S. D., \& Graham, L. T. (2012). A Review of Facebook Research in the Social Sciences. Perspectives on Psychological Science, 7(3), 203-220.

[27] Wright, K. B. (2006). Researching Internet-Based Populations: Advantages and Disadantages of Online Survey Research, Online Questionnaire Authoring Software Backages, and Web Survey Services. Journal of Computer-Mediated Communication, 10(3), 1-15. 